\title{
Choosing between the Conventional Plates, Locking Plates, or Iliosacral Screws for Sacroiliac Joint Dislocation: A Biomechanic Comparative Study
}

\author{
Trixie Brevi Putri ${ }^{1}$, Erwin Ramawan ${ }^{1}$, Mohammad Zaim Chilmi ${ }^{1}$, \\ Kukuh Dwiputra Hernugrahanto ${ }^{1}$, Jifaldi Afrian Maharaja Dinda Sedar ${ }^{1}$, \\ Fundhy Sinar Ikrar Prihatanto²
}

${ }^{1}$ Department of Orthopedic \& Traumatology, Dr. Soetomo General Hospital/Universitas Airlangga, Surabaya, Indonesia ${ }^{2}$ Department of Anatomy \& Histology, Faculty of Medicine, Universitas Airlangga, Surabaya, Indonesia

\section{ABSTRACT}

Background: This study examines the comparison of biomechanical strengths of three kinds of the most familiar implants available in Indonesia: conventional and locking sacroiliac plates and screws, also iliosacral screws. Despite the common thought that iliosacral screws are preferred compared to conventional plates and screws due to its biomechanic superiority, this study tested whether the locking plates and screws could offer an alternative.

Materials and Methods: This study was an in vitro experimental study with a Randomized Post Test - Only Control Group Design using pelvic bones from male cadavers aged 20-50 y.o. Twelve samples were divided into three treatment groups and one control group. Group CPS was fixed with two conventional plates, LPS was fixed with two locking plates, IS was fixed with two iliosacral screws, and control group with sacroiliac joint was left intact. Each group was given an increasing load until a vertical shift of the sacroiliac joint $\geq 2.0$ $\mathrm{mm}$ was obtained.

Results: The average force load for $2 \mathrm{~mm}$ displacement among the fixation systems being tested shows a statistically significant difference $(p<0.05)$. Load failure force for $2 \mathrm{~mm}$ displacement in the group LPS has the highest average $(591.33 \pm 56.08 \mathrm{~N})$ compared to the group IS (583.67 $\pm 73.56 \mathrm{~N})$ and group CPS ( $574 \pm 106.05$ N).

Conclusion: Biomechanically, the fixation system using two locking anterior sacroiliac plates and screws is more stable than the iliosacral screws and conventional sacroiliac plates and screws.

Keywords: biomechanics; sacroiliac joint dislocation; anterior plating sacroiliac; locking; iliosacral screwing Level of Evidence: II

This is an open access article under the CC-BY-SA license. Article history:

Submission

Revision

Accepted
October $22^{\text {nd }}, 2020$

December $23^{\text {th }}, 2020$

December $25^{\text {th }}, 2020$
Corresponding Author:

Erwin Ramawan, M.D,

Dr. Soetomo General Hospital/Universitas Airlangga,

Surabaya, Indonesia.

Email: erwin-ramawan@fk.unair.ac.id 
Introduction

The pelvic ring is an essential part of the human skeletal system. It has two important functions of protecting the pelvic organs and providing stability to support body weight. Pelvic stability is obtained through the osteoligamentous structure's ability to withstand physiological stress without abnormal deformation. ${ }^{1,2}$ Fractures and injuries to the pelvic ring, whether related or not with severe trauma, usually occur in the range of $2-8 \%$ of all musculoskeletal fractures. ${ }^{3-5}$ In the United States, it is estimated that pelvic fracture occurs in 37 of 100,000 people per year. ${ }^{6}$

The pelvic ring's stability depends primarily on the sacroiliac complex's integrity, which holds the posterior load..$^{7-9}$ The implant of choice for sacroiliac joint dislocation is one of the neverending debatable topics among orthopedic surgeons. ${ }^{10}$ Many implant choices are available in the market. This study is a biomechanical study that aims to compare the biomechanical stability of three kinds of the most familiar implants available in Indonesia: conventional and locking sacroiliac plates and screws, also iliosacral screws. This study tested the locking plates and screws that were not commonly explored in Indonesia's daily practice to treat pelvic ring injury. We hypothesize that sacroiliac joint dislocation fixed with locking plates and screws will offer an alternative.

\section{Material and Methods}

\section{Study Design}

This research is an in vitro experimental study with a Randomized Post Test - Only Control Group Design. The study was conducted in the Anatomic laboratory in our institution and the Special Testing Laboratory of the Faculty of Civil, Environmental, and Earth Engineering. This study had already approved by the IRB of the authors' affiliated medical faculty.

\section{Samples Criteria}

In this study, the experimental unit was pelvic bones from 5 male cadavers aged between 20-50 years preserved less than three years before the experiment. Any pelvic with gross anatomical deformity and damages due to injuries, any congenital abnormalities, joint inflammatory or infection disorders, bone tumors were excluded.

\section{Study Stages}

This study's implementation was divided into three stages-first, cadaveric pelvic bone preparation and internal fixation assembly. Second, a biomechanical test to determine the stability of all groups and data recording. The third is the data collecting and analysis of research data.

\section{Preservation, Preparation, and Sacroiliac Joint Disruption Modeling in Specimens}

Preservation had been done with $10 \%$ formalin, and the samples were cleaned from all soft tissues that adhered to it. The samples were from the L5 vertebral body, sacrum, and two innominate. Pelvic ring ligaments and pubic symphysis were separated for the treatment groups. These were the dissected ligaments of pelvic ring: Posterior Sacroiliac (both long and short), Interosseus Sacroiliac, Anterior Sacroiliac, Sacrotuberous, Sacrospinous, and lliolumbar. While in the control group, only pubic symphysis was separated.

\section{Fixation of Specimens}

The treatment sample was then divided randomly (simple random) into three treatment groups, namely group CPS (fixation with conventional plates and screws), group LPS (fixation with locking plates and screws), group IS (fixation with iliosacral screws), and one control group. Each pubic symphysis was fixated by first author using a conventional $3.5 \mathrm{~mm} 316 \mathrm{~L}$ stainless steel five holes-small DCP plate and screws. The method of fixation is illustrated in figure 1. 


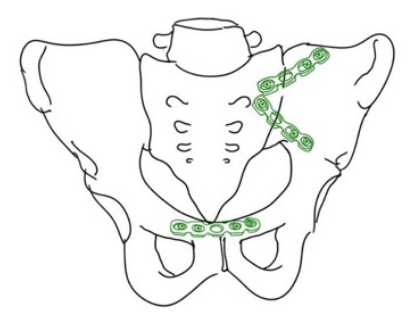

A.

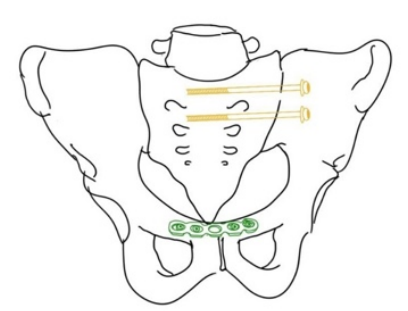

C.

Figure 1. Method of Fixation. A. Group CPS (Conventional Plate and Screws) , B. Group LPS (Locking Plate and Screws), C. Group IS (Iliosacral Screws), and D. Control.

Group CPS used two conventional $3.5 \mathrm{~mm}$ precontoured 316 L stainless steel four holesreconstruction plate (ORMED ${ }^{\oplus}$ ). Drilling was done with a 2.7 drill bit. The hole was tapered with a cancellous taper. Later on, $3.5 \mathrm{~mm}$ cancellous screws were put on (one screw on the side of the sacrum and two screws on the side of the ilium). In group CPS, two plates were arranged at an angle of $60^{\circ}$ to each other.

Group LPS used two locking $3.5 \mathrm{~mm}$ pre-contoured 316 L stainless steel four holes-reconstruction plate (ORMED ${ }^{\circ}$ ). Drilling was done with a locking 2.8 drill bit. Then $3.5 \mathrm{~mm}$ self-tapered self-locking screws were put on (one screw on the side of the sacrum and two screws on the side of the ilium). In group LPS, two plates were arranged at an angle of $60^{\circ}$ to each other.

Group IS used K-wire threaded installation for guidance. Drilling was done with the cannulated drill bit. Then two $316 \mathrm{~L}$ stainless steel $6.5 \mathrm{~mm}$ cannulated (long threaded $-32 \mathrm{~mm}$ ) screws (ORMED ${ }^{\oplus}$ ) were installed from the posterior iliac fossa toward S1 and S2 bodies.

Control group was left without fixation since the sacroiliac joint remained intact.

\section{Biomechanical Test}

The displacement (vertical shift) between the sacrum and the ilium for each group was measured after the loading. Displacement was measured by comparing the distance between the two points before and after being given continuous loading. The tools and materials used were Shimadzu AG-x5kN autograft, pliers, and digital calipers. Biomechanical tests were carried out by the constant loading on the upper part of the $L 5$ sacral body using an autograft. Pelvic bones were placed in a fixation device on the autograft machine. On both sides of the pelvic bone (i.e., on the side of the ilium and the side of the sacrum), each point was marked by a dot to perform the measurement.

In this study we only evaluate for one specific force - vertical shear - to avoid bias that came from another force types (anteroposterior or lateral compression) that will damage the bone microarchitecture and could affect another observation to be done. The vertical shear loading force of the autograft machine was given starting at $0 \mathrm{~N}$, then rising at a $1 \mathrm{~mm} /$ second speed until a shift (translation) is obtained at the sacroiliac joints of $25 \mathrm{~mm}$ and $10 \mathrm{~mm}$. The force applied was noted when reaching these three shifts. The initial load was given at $100 \mathrm{~N}$ in the vertical direction; the load was increased until a shift (translational) was obtained from the sacroiliac joint $\geq 2.0 \mathrm{~mm}$. A picture when performing the biomechanical test is shown in Figure 2. To ensure that each sacroiliac joint being tested will not affect the contralateral side, a holder device was made to create a model of unilateral stance for each test. Moreover, every sacroiliac joint with implanted devices that are already being tested were not being used for testing another implant system to maintain the microstructure of the bone. 


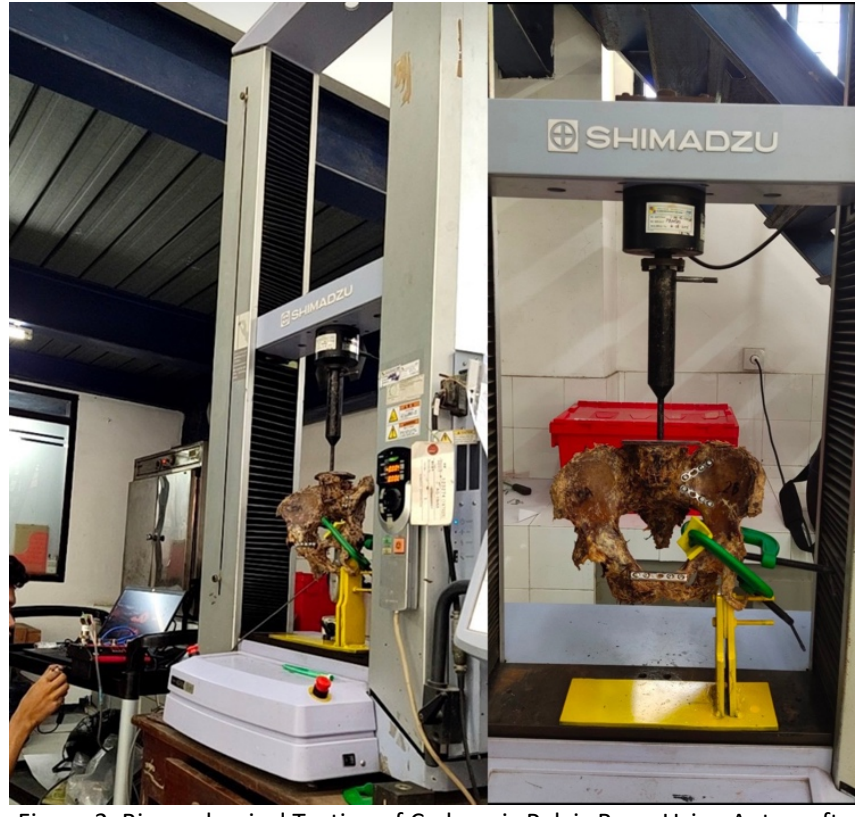

Figure 2. Biomechanical Testing of Cadaveric Pelvic Bone Using Autograft. A particular holder device was made to fix the pelvic during the experiment.

\section{Statistical Analysis}

The analysis was performed statistically using SPSS software version 23.0 (SPSS Inc., Chicago, IL, USA). The determination of $\alpha$ value was 0.05 . The data normality test used the Shapiro Wilk test, and the data homogeneity test used the Levene test. Data intervals or ratios, normal distribution, and variations between the same groups were done using one-way ANOVA test with Friedman test as Post hoc analysis.

\section{Results}

This is an experimental analytic study comparing the biomechanical strength of fixation in the dislocation of sacroiliac joints between CPS, LPS, and IS. In Figure 3, the comparison of the load to failure upon axial forces among fixation groups is shown.

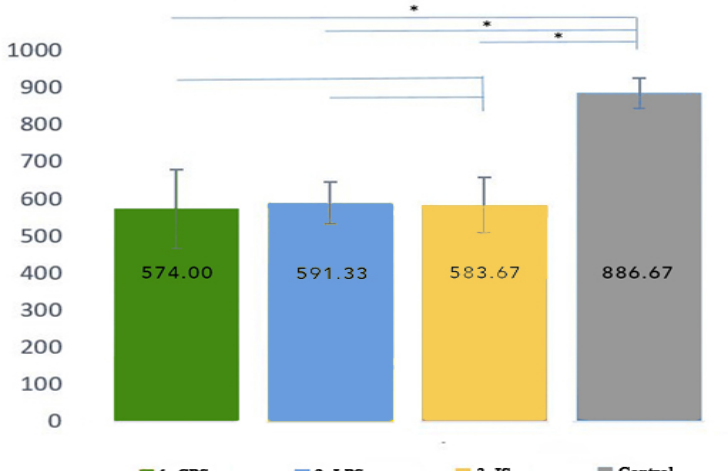

Copyright (C 2021 the author(s) | http://thehipkneejournal.id
Figure 3. Comparison of the load to failure upon axial forces among fixation groups : 1. Group CPS (Conventional Plate and Screws), 2. Group LPS (Locking Plate and Screws), 3. Group IS (Iliosacral Screws), and Control. Data are presented as mean $\pm S D . n=3 /$ group, ${ }^{*}: p<0.05$

The statistical analysis using the One-way ANOVA test in Table I shows a significant difference between the average load forces that cause a $2 \mathrm{~mm}$ load failure based on a fixation system $(p=0.002)$. This result indicates that the load failure force of $2 \mathrm{~mm}$ in group LPS has the highest average $(591.33 \pm 56.08 \mathrm{~N})$ compared to other groups. There is no significant difference between the mean force loads that cause either 5 $\mathrm{mm}$ or $10 \mathrm{~mm}$ load failure based on a fixation system ( $p=0.147$ and $p=0.066$, respectively). The Post hoc Tukey HSD analysis shows a significant difference between the mean force loads that caused a two $\mathrm{mm}$ shifting failure between the control group and group IS $(p=0.004)$, the control group and group CPS ( $p=0.004)$, the control group and group LPS $(p=0.005)$.

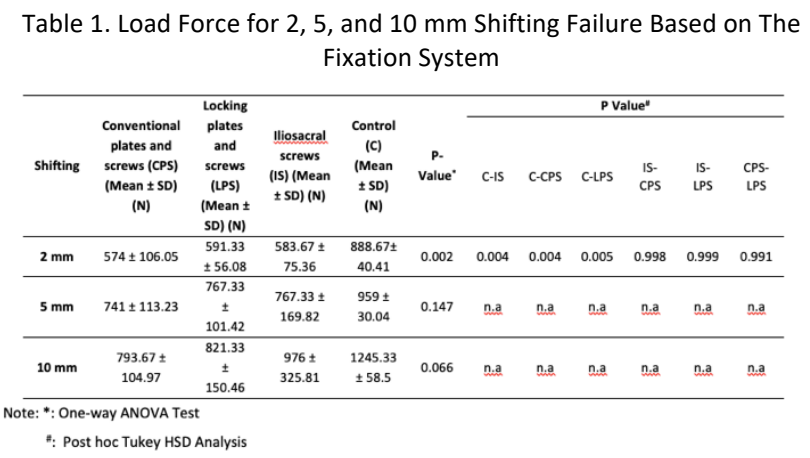

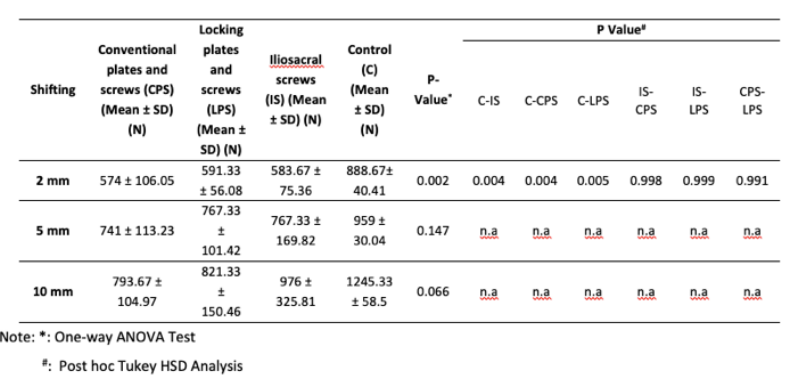

Discussion

There are various methods for fixating sacroiliac joint dislocation, including iliosacral screws, anterior or posterior sacroiliac plates and screws, sacral bars, and triangular osteosynthesis. ${ }^{11}$ Fixation of the sacroiliac joint allows for open and direct reduction with the drawbacks requiring a wider incision and approach to the sacroiliac joint to better view the surgery. In comparison, fixation with iliosacral screws requires adequate operator skills, good dimensional understanding, fluoroscopy support in surgery, and a greater risk of neurovascular injury due to reduction and implant placement. ${ }^{12-}$ ${ }^{14}$ The displacement of fragments indicates the 
stability of a fixation system in response to certain loads. Stiffness of fixation construction is the ratio of the load applied to the displacement between fragments. ${ }^{15,16}$ The stability of various internal fixation types of the sacroiliac joint has been investigated. Research on the biomechanical strength of plates using locking screw for sacroiliac joint fixation has not been done much in Indonesia.

This study aims to compare stability and shift in dislocation of sacroiliac joints fixed using CPS, LPS, and IS. In this study, the results obtained a significant impact that the greatest load force for $2 \mathrm{~mm}$ load failure was found in the LPS compared to another two fixation systems. This indicates that this system is the most stable than the other two methods, followed by IS and CPS. Alike with other studies, the intact pelvis has the greatest stability. ${ }^{17,18}$

The stability of sacroiliac joints fixation using anterior sacroiliac plates and screws, which commonly uses conventional plates and screws in Indonesia, is more inferior than iliosacral screws. This study shows that the locking system obtained better stability compared to conventional systems and even iliosacral screws. ${ }^{19}$

We admit that our study has several limitations. Bias might come from the diversity of the cadaver pelvic bone mineral density, and conditions in cadaver bones may vary from the actual in vivo human pelvic bone. We were unable to control this bias due to the limited number of cadavers available and these were scarce and very valuable specimens to obtain. Another bias also from the small sample number due to the scarcity and availability of the cadaver samples. Whereas for the ideal statistic, the sample number equal to three times the current study. We also did not perform the post-fixation radiograph evaluation in this study. To equalize the scarcity of the sample number and ensure the bone quality to be tested will not be affected by another treatment, we made a holder device to create a model of unilateral stance. Every sacroiliac joints with implanted devices that are already being tested were not being used for testing another implant system to maintain the microstructure of the bone.

Prospective clinical research is needed to assess the stability, function, and complications of the locking sacroiliac plates and screws in vivo. For future research, the finite element analysis model's usage should be explored more due to its practicality and ability to simulate the physical bone condition and test the microcosmic mechanical research to be a good complement for a biomechanical study. Many aspects could be studied, such as stress distribution, and the classical method using real cadavers is getting more difficult nowadays to be approached.

\section{Conclusion}

This study shows that the biomechanical fixation system using two locking sacroiliac plates and screws is more stable than the iliosacral screw system and conventional sacroiliac plates and screws with significant differences. The locking plates and screws offer two benefits: it is proven biomechanically stable compared to another two usual implants and its applicability when the fluoroscopy is not available. The direct reduction also hinders the complication from indirect reduction due to anatomical variances and technical difficulty identifying the "safe zone" during percutaneous iliosacral screwing.

\section{Conflict of Interest}

The authors affirm no conflict of interest in this study

\section{Acknowledgement}

None 


\section{References}

1. Khurana B, Sheehan SE, Sodickson AD, Weaver MJ. Pelvic ring fractures: What the orthopedic surgeon wants to know. Radiographics. 2014;34(5):1317-33. doi: $10.1148 / \mathrm{rg} .345135113$

2. Gorczyca J, Hearn T, Tile M. Biomechanics and Methods of Pelvic Fixation. In: M. Til. Davos: AO Publishing; 2015. 116-129 p.

3. Pan RH, Chang NT, Chu D, Hsu KF, Hsu YN, Hsu JC, et al. Epidemiology of orthopedic fractures and other injuries among inpatients admitted due to traffic accidents: A 10-year nationwide survey in Taiwan. Sci World J. 2014;2014(Ci). doi: 10.1155/2014/637872

4. Pereira GJC, Damasceno ER, Dinhane DI, Bueno FM, Leite JBR, Ancheschi B da C. Epidemiology of pelvic ring fractures and injuries. Rev Bras Ortop. 2017;52(3):260-9.

5. Yang N-P, Chan C-L, Chu D, Lin Y-Z, Lin K-B, $\mathrm{Yu}$ C-S, et al. Epidemiology of hospitalized traumatic pelvic fractures and their combined injuries in Taiwan: 2000-2011 National Health Insurance data surveillance. Biomed Res Int. 2014;2014.

6. Davis D, Foris L, Kane S, Waseem M. Pelvic Fracture [Internet]. StatPearls Publishing. 2020.

7. Van Zwienen CMA, van den Bosch EW, Snijders CJ, Kleinrensink GJ, van Vugt $A B$. Biomechanical comparison of sacroiliac screw techniques for unstable pelvic ring fractures. J Orthop Trauma. 2004;18(9):589-95. doi: 10.1097/00005131-200410000-00002

8. Berber O, Amis AA, Day AC. Biomechanical testing of a concept of posterior pelvic reconstruction in rotationally and vertically unstable fractures. J Bone Jt Surg - Ser B. 2011;93 B(2):237-44. doi: 10.1302/0301-620X.93B2.24567 9. Elhence $A$. Internal fixation of pelvic injuries. J Orthop Traumatol Rehabil. 2014;7(1):19. doi: 10.4103/0975-7341.134004

10. Comstock $\mathrm{CP}$, van der Meulen $\mathrm{MCH}$, Goodman SB. Biomechanical comparison of posterior internal fixation techniques for unstable pelvic fractures. J Orthop Trauma. 1996;10(8):517-22.
11. Moed B., Kellam J., McLaren A, Tile M. Internal Fixation for The Injured Pelvic Ring. In: $M$. Til. Davos: AO Publishing; 2015. 217-293 p.

12. Egol KA, Kubiak EN, Fulkerson E, Kummer FJ, Koval KJ. Biomechanics of locked plates and screws. J Orthop Trauma. 2004;18(8):488-93. doi: 10.1097/00005131-200409000-00003

13. Khaled SA, Soliman O, Wahed MA. Functional outcome of unstable pelvic ring injuries after iliosacral screw fixation: single versus two screw fixation. Eur I Trauma Emerg Surg. 2015;41(4):387-92. doi: 10.1007/s00068-0140456-x

14. Tile $\mathrm{M}$, Hearn $\mathrm{T}$, Vrahas M. Biomechanics of The Pelvic Ring Chapter. In: M. Til. Vol. 4. Davos: AO Publishing; 2015. 32-45 p.

15. Ueno $\mathrm{FH}$, Pisani MJ, Machado AN, Rodrigues FL, Fujiki EN, Rodrigues LMR. Biomechanical study of the sacroiliac fracture fixation with titanium rods and pedicle screws. Acta Ortop Bras. 2015;23(3):154-7. doi: 10.1590/1413-78522015230300970

16. Şahin O, Demirörs H, Akgün RC, Tuncay IC. Internal fixation of bilateral sacroiliac dislocation with transiliac locked plate: A biomechanical study on pelvic models. Acta Orthop Traumatol Turc. 2013;47(6):411-6. doi: 10.3944/AOTT.2013.2840 17. Zhang $L$, Peng $Y$, Du C, Tang $P$. Biomechanical study of four kinds of percutaneous screw fixation in two types of unilateral sacroiliac joint dislocation: A finite element analysis. Injury. 2014;45(12):2055-9.

doi: 10.1016/j.injury.2014.10.052

18. Chen W, Pan Z jun, Chen J song. Biomechanical research on anterior double-plate fixation for vertically unstable sacroiliac dislocations. Orthop Surg. 2009; doi: 10.1111/j.1757-7861.2009.00017.x

19. Dickson K, Munz J. Locked Plating: Biomechanics and Biology. Tech Orthop. 2007;22(4):E1-6.

doi: 10.1097/BTO.0b013e31814a6337 